\section{The Return of Caribou to Ungava}

By A.T. Bergerud, Stuart N. Luttich, and Lodewijk Camps. 2008. McGill-Queen's University Press, Canada. 586 pages, 49.95 CAD, Cloth.

Between the years 1958 and 1984, the George River caribou herd of the northern reaches of Labrador and Quebec (Ungava Peninsula) increased from 15000 animals with a range of $90000 \mathrm{~km}^{2}$ to well over 600000 animals covering a range of $750000 \mathrm{~km}^{2}$ - the largest caribou herd in the world. This is their story.

It is a unique story - a story that was hard to come by. Long-term data sets are not common in ecology. For over 20 years, the senior author, former chief biologist with Newfoundland and Labrador's Wildlife Division, and his co-authors tracked and monitored these nomads across the taiga and tundra of the sub-Arctic regions of eastern Canada.

If you wish to learn about the caribou, read this book. The book is mammoth, an opus magnum, chock full of data and insight into the lives of the iconic wanderer of the north. It is a rare type of work. Collection of longterm data on itinerant mammals in large wilderness settings does not come easy. Never mind the consistent institutional and financial support that is required for such research. That, in itself, is a feat. However, think of itinerant animals travelling relentlessly over thousands of square kilometers. How do you study such moving targets? For years, the authors had to find the caribou (not an easy task in those early days), capture them, and then wrestle them, measure them, sample them, collar them, and then free them not too much worse for wear. Behind these simple pages of figures and tables is an amazing wealth of field wisdom and scientific savvy.

The book attempts to answer ecology's classic question: What causes the size of animal populations to fluctuate? Each of the 16 chapters attempts to add a piece to the puzzle - historic fluctuations, forage and range, recruitment and mortality, limiting factors and the use of space, calving and migration. The authors cover it all and bring you along for the ride as you follow the roaming caribou in search of food on the arctic summer prairies, high altitude calving grounds safe from predatory wolves and bears, and relief from parasitic insects, flies and mosquitoes. Detailed as well, are the hefty changes in body and antler growth along with physical and physiological conditions as the animals calve, grow, breed and migrate.

Hundreds of figures and tables distill the years of field and lab measurements and tracking data. The long-term data reveal temporal and spatial trends and patterns that are intellectually satisfying and a beauty to behold. The 36 colour plates at the beginning of the book are magnificent, revealing wonders of landscape and caribou few have witnessed.

This book is a wealth of information that few people are able to muster. It will therefore serve as a classic study of caribou demographics and population biology. Future caribou research will need to consider this monumental endeavor. However, the vast wealth of information is also the book's weakness. The book reads at times as simply one fact after another. The book could have benefited from a judicious editing. The reader can get lost in the prodigious detail. The writing style is more akin to what one would expect in scientific articles rather than in a work that was presumably destined for a wider audience. In addition, the insertion between chapters five and six of an unnumbered chapter on the Mushuau Innu and the caribou by a separate author appears to be an afterthought and would have been better placed as an appendix. The one appendix entitled "summer energy budgets for lactating females" also seems out of place, as if the authors wanted to squeeze in every bit of available data.

Will future generations still witness the lonesome trek of Rangifer across the northern reaches? As this book was published, the Government of Newfoundland and Labrador announced a $\$ 15$ million program to examine the decline in the Island caribou population from recent highs of $80000-100000$ animals to current levels of $40000-50000$ animals. The future of the caribou will depend largely on us. The pressures on caribou populations are no longer simply predators or parasitic insects. Human pressures are increasing across the landscape. Bergerud et al. have gifted us with an intimate gaze on a natural wonder of the world. What a tragedy if future generations had no idea about what Bergerud et al. were talking.

By definition, book reviewers are not the book's authors. That will not prevent me, however, from expressing a wish or better still, a plea - a plea for a future book, a simpler, shorter trade book that tells the story of the authors' passionate hope for the continuation of the caribou's "endless march" into the future. They have the experience. They have the passion. Maybe they have some suggestions. I hope that their story will enable future generations to study the caribou, to protect them and to care for them. Such a legacy will ensure "the return of the caribou to Ungava."

JOHN MCCARTHY

5935 Iona Drive, Vancouver, British Columbia V6J 1J7 Canada 